\title{
Introduction
}

The career of South Korean filmmaker Im Kwont'aek spans over fifty years and one hundred films. His 1978 film The Genealogy (Chokpo) marks an important point in that career, for it shows a departure from the type of films he made throughout the 1960 and 197 os. $^{1}$ Based on a novella by the Japanese writer Kajiyama Toshiyuki, the film reflects Im's self-conscious and serious efforts to move away from the production of low-budget genre films. ${ }^{2}$ The Genealogy is one of his most thematically coherent and stylistically mature works of the 1970s, foreshadowing the preoccupation with national culture and tradition that would later be a prominent theme in his oeuvre. The film is set in the late colonial period, when the Japanese colonial government was increasing its pressure on Koreans to comply with the cultural assimilation policy aimed at converting Koreans into loyal imperial subjects. Its narrative focuses on Tani, a young Japanese government official who is assigned to convince the Korean patriarch Sŏl Chinyŏng to obey the new policy (changssigaemyŏng in Korean) under which Koreans would adopt Japanese names. The film offers a complex narrative of Korean cultural resistance to colonial rule as shown from Tani's conflicted perspective, which is both colonialist and sympathetic to the Korean opposition. ${ }^{3}$ In addition, the film's exquisite mise-en-scène both features and manifests the themes of Korean tradition and cultural nationalism in visual terms. ${ }^{4}$

But one image conspicuously deviates from the film's overall realistic visual style. It appears early in the film, when Tani confronts his boss's criticism of his lackluster performance at work. Dejected, Tani walks off to a corner of the office, stands by the window, and lights a cigarette. Through the window we see the Government-General Building of Korea-but not the actual building, for it is 


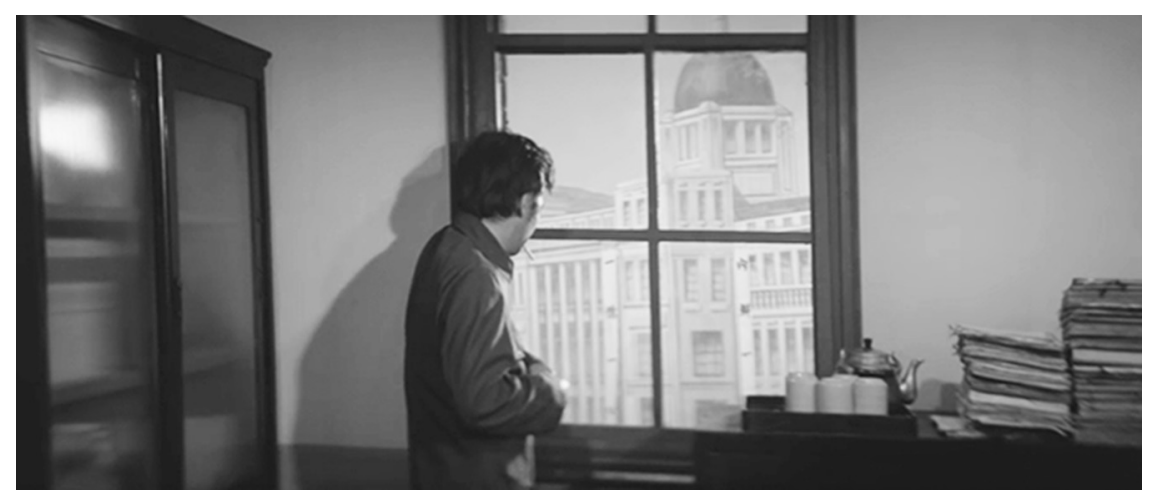

FIGURE 1. Tani stands by the window against the backdrop of the distant GovernmentGeneral Building in The Genealogy. Courtesy of the Korean Film Archive.

neither cinematographically captured nor photographically rendered. Instead, it appears as a flat painted image whose artificiality is visible in the poorly rendered details, blurry contours, and overexposed color, creating an odd but momentary distanciation for viewers. Furthermore, the slanted angle is improperly aligned with the angle of the window frame and with Tani in the foreground, leading to a perceptual disarray comparable to a failed trompe loeil.

The odd image of the building is in sharp contrast to the rest of the film, which largely adheres to the formal conventions of popular narrative film. ${ }^{5}$ A question is then: What do we make of a building image that is out of sync with the film's meticulous visualization of Korean tradition and custom set in opposition to an oppressive colonial regime? To be sure, either Im's authorial intent or his filmmaking circumstances might account for the staging of such an image. ${ }^{6}$ Yet the building's "exceptional" appearance raises questions about the history of the colonial period with which it is forever associated in Koreans' memories.?

Completed in 1926, the neoclassical building of the Government-General of Korea served as the massive headquarters of the Japanese colonial administration. It stood on the cleared space where the central palace of the Chosŏn dynasty, Kyŏngbok Palace, had once stood, and it subsequently became the icon of Japanese colonial rule in Korea. After Korea's liberation in 1945, the same landmark turned into the headquarters of the American military occupation (1945-48) and later became the central government building of South Korea. Renamed Capitol Hall (Chungangchŏng), it was the seat of almost every major historic event and political ceremony in the modern history of South Korea. ${ }^{8}$ Then came the controversies and reversals of the new civilian government-led "national spirit restoration" campaign in the mid-199os. Eradication of the colonial landmark was proposed to revive the symbolic geography of the palace that colonial spatial politics had effectively displaced and erased. ${ }^{9}$ The building was finally demolished in 1995 , on the 
fiftieth anniversary of Korea's liberation from Japan, and since then the original palace has been partially reconstructed. ${ }^{10}$

At stake in the controversy were competing viewpoints and memories of the building's historical associations and symbolic meanings. As a "communicative device," the building became a site where these discursive claims and political and historical views intersected at particular moments in South Korean history. ${ }^{11}$ Implicit in the discourses surrounding the building was a naturalized way of seeing that the postcolonial society had cumulatively constructed toward the remnants of the colonial past: not outright repudiation, as in the more usual stance of oppositional nationalist politics, but a more subtle form of disavowal carried out by strategies of reworking, recontextualizing, and erasing the ideas and symbols of past colonial power. ${ }^{12}$

The interjection of the artificial image of the building in The Genealogy alludes to this kind of disavowal. ${ }^{13}$ The image causes an inconsistency in the visual field, offering a kind of refracted view of the building that would otherwise signal historical continuity between the former colonial regime and the present postcolonial regime. While the image remains perceptible, its flat artificial surface de-frames the building from its historical aura and context and thereby weakens them. Its artificiality is not, therefore, a defect of style but a self-conscious aesthetic choice in the larger chain of significations that South Korean cinema constructed in its inculcation of anticolonial nationalism. ${ }^{14}$ In postcolonial cinema, the concept of disavowal illuminates understated but persistent strategies, norms, or rationales for representing the colonial period. ${ }^{15}$ Ways of seeing or imagining the past furthermore contributed to the knowledge production that was integral to the formation of a South Korean national subjectivity uniquely influenced by the bipolar order of the Cold War.

My purpose in this book is to bring attention to the configuration of the colonial past in South Korean cinema from 1945 through the 1970 s supplemented by a few from later decades. ${ }^{16}$ The representation of colonialism is related not only to the stubborn legacies of nationalism in South Korea but also to the nation's appraisal of the colonial past under the intensifying bipolarization of politics that led to Korea's prolonged partition.

I first seek to cast light on how postcolonial cinema transcoded the dominant, that is, nationalist, view of history into accessible narrative and imagery for Korean film viewers. As I will illustrate, the postcolonial rendition of anticolonial nationalism involves more than simply showing Korean people collectively resisting colonial violence and domination. ${ }^{17}$ A variety of formal choices and considerations, including new narrative tropes and visual imagery, generic elements and conventions, and spatial configurations, came into play to enhance and further the stories of individuals and groups in struggle. Institutional forces and social factors also intervened. For instance, state policies and regulations, commercial interests 
of the film industry, transcultural film exchanges, and ideas of national culture all intersected with filmmaking practices. Both filmic representation and discursive and industrial practices therefore receive attention in this book.

Since its liberation in 1945, South Korea has produced over two hundred films that are set in the colonial era (1910-45). Not only is that number impressive, but a breakdown by decade shows a pattern of consistent production output: there has been no discernible drop in production of colonial-themed films. ${ }^{18}$ This consistency over time suggests that the anticolonial nationalist impulse is an ideological constant in South Korea's cultural production and that nationalist ideology is embedded in postcolonial society. ${ }^{19}$ Such an impression is generally supported by scholars of modern Korean history, who remind us of the structural significance of the colonial experience to the subsequent formation of postcolonial national culture in South Korea. The idea of the nation and its experience is based on the nationalist ethos that was formed in opposition to colonialism, and in film that ethos has served as the grand thematic matrix for individual treatments of widely differing subjects and issues. Consequently, one might imagine that films depicting the colonial experience would have enjoyed critical accolades in South Korea. ${ }^{20}$

Yet the critical appraisal presents a different picture. First, colonial-themed films are largely missing from lists of the film canon of South Korea. ${ }^{21}$ Scholars have been slow to examine the subject of colonial representation in films, and only a few films have received their attention. The overall critical lack of interest may be due to a perception that these films are propagandistic. ${ }^{22}$ Whatever their actual shortcomings, films on the colonial past have clearly not been regarded as the best examples of Korean cinema. Instead, they have been dismissed as middlebrow cultural productions that have functioned to organize the larger precepts of political ideology in understandable terms. ${ }^{23}$ The problem of critical indifference also evidences a peculiar vacuity at the core of postcolonial cultural criticism of colonialism itself.

This vacuity, according to Heonik Kwon, is postcolonial criticism's tendency to neglect the close connection between the postcolonial appraisal of colonialism and the political history of the Cold War. Whereas postcolonial criticism divided colonialism into two schemas-the official demise of the institutional order and the lingering presence of colonial cultural imaginaries-it failed to include the greater ramifications of the Cold War order for ex-colonial societies and cultures. ${ }^{24}$ Taking a cue from Kwon, I approach the representation of colonialism in South Korean films as a site of inflection that the new Cold War bipolarity imposed upon postcolonial culture. ${ }^{25}$ The semantic struggle over the colonial experience may appear tangential to the existing Cold War discourse and culture. However, I argue that it is integral to the larger politics of knowledge production and cultural meaning making that sustained the liberal capitalist vision of the world and the 
US-dominated bipolar ordering. This means that the films that uphold an oppositional view toward colonial rule can be interpreted not only as outlets for nationalist fervor but also as repositories for the refracted signifiers of Cold War optics, as exemplified in the building image of The Genealogy. They refer to the ongoing negotiation and depoliticization of the local (i.e., colonial) issues that occurred under the bipolar order that the United States imposed on a global scale. To properly historicize postcolonial cultural productions, one needs to read beyond the surface signs of anticolonialism. This work hence brings attention to the lacunae and aporia of "overcoming colonialism" that South Korean cinema has rendered visible in diverse ways.

\section{A BRIEF HISTORY OF COLONIAL KOREAN CINEMA}

The arrival of cinema in Korea dates back to the early twentieth century, when the country entered a series of tumultuous and prolonged crises that resulted in its annexation by Japan in 1910. The first film exhibition took place in 1903 in Seoul as part of a promotional campaign by an American electric company. Most films shown to Korean audiences at the time were of foreign origin, and they offered the viewing public access to foreign, modern, and exotic worlds outside Korea. Politically, the Japanese colonization of Korea (1910-45) led to seismic and violent changes in nearly all aspects of Korean life. The colonial administration placed rigid disciplinary measures upon the Korean populace to construct a subjectivity in accordance with the colonialist logic of domination and control. Under the banner of civilization and enlightenment, various cultural policy measures were introduced to regulate Korean social activities and cultural productions. Filmmaking was no exception.

Though Korean cinema slowly grew to become a formidable popular medium, it consistently faced institutional hurdles and challenges on many fronts. A lack of domestic funding sources, an insufficient infrastructure for a distribution network, and a shortage of exhibition spaces hindered the development of domestic commercial filmmaking in the early years. The first Korean film arrived in the form of a kino-drama called Righteous Revenge (Uirijŏk kuto) in 1919. It was a hybrid film used as a short vignette for backstage imagery in theatrical stage productions. Then, in 1922, Korea witnessed the release of the first commercial feature film, Chunhyangjŏn, which was based on popular folklore. A silent film boom soon ensued, and over seventy domestic films were released in the late 1920s, all vying for audiences in the expanding film business. In particular, $\mathrm{Na}$ Ungyu's Arirang (1926) galvanized public enthusiasm for Korean cinema, as the film tapped into the nationalist sentiment of the populace. The success of Korean film in the $1920 \mathrm{~s}$ and early 1930 s was due to several factors: talented filmmakers, shrewd business leaders, and the overall expansion of the film industry. Film exhibition showed 
conspicuous growth as movie theaters opened and thrived in major cities. The colonial cultural policy also helped create a boom, though only a brief one, for the film industry. ${ }^{26}$

The conversion to talkie films posed a major challenge for Korean filmmakers, for this new type of film demanded substantial capital investment and technological expertise as well as a new sensibility regarding the audiovisual synthesis of filmmaking. ${ }^{27}$ Politically, Japan's full-scale invasion of China in the late 1930 s triggered a drive for wartime mobilization in Korea, including the colonial government's implementation of various and complex forms of control over cultural productions. A series of decrees made Korean filmmakers highly conscious of the government control and censorship of filmed materials. In the early 1940s, the government cut back on the showing of popular films from the West in Korea and subsequently consolidated Korean film production and distribution companies into a single encompassing propaganda machine. The state administration and agencies worked in tandem to promote films with explicit propaganda messages, such as justifications of the colonial policy of cultural assimilation known as naisen ittai ("Japan and Korea as one body," naesŏn ilche in Korean). The situation forced Korean filmmakers to navigate and negotiate complex pressures inside and outside the official control of the state. ${ }^{28}$ Consequently, Korean cinema became a political tool of the Japanese state from 1936 to 1945, as most films valorized colonial policies that aimed at the total assimilation of Koreans into the Japanese imperial body.

The late colonial "collaborationist" films from this period in particular bring into sharp relief the political, but also formal, orientation of postcolonial cinema. On the surface, these films illustrate the theme of conversion, depicting the participation of Koreans in the war effort as necessary and noble acts for the empire. ${ }^{29}$ Making these films involved the consideration of many factors, as filmmakers had to operate under the tightening grip of the colonial administration. ${ }^{30}$ The interpretive tendency has been to point out how signs of ambivalence or melancholia, typically inscribed on the bodies of colonized male Korean characters, escape the Japanese administration's pressure on the film industry to uphold and naturalize a policy of assimilation and total mobilization. ${ }^{31}$ For example, the ailing body of the Korean male protagonist in Yi Pyŏngil's Spring of the Korean Peninsula (Pando-ŭi Pom, 1941) alludes to the troubled split condition of the colonial nation forced to take part in the making of naisen ittai rhetoric. ${ }^{32}$

My interest here does not lie so much with the elaboration of the gray zone of ambivalence that Korean characters embody and register in relation to the wartime mobilization. ${ }^{33}$ Rather, I want to shift focus to the spatialized pattern of mobilization that brings together two different registers of meaning: the inner psychic state of Koreans and the external world of empire. The melancholic or exhausted body has often been interpreted as the troubled, if not resistant, Korean national under the duress of political indoctrination. Such figures function as placeholders 
in a space that is bound to be filled with "positive" values. This trope then anticipates the gradual development or advent of a change of heart, culminating in the national's decisive entry into the project of empire building. Procedural in nature, these films portray the inner torment of Koreans who are ambivalent and hesitant toward this project as a necessary step to underscore their destined gravitation toward the larger system of meanings, namely, empire. ${ }^{34}$ Hence, late colonial collaborationist films achieve something unprecedented in Korean film history: they make visible the interiority of the colonized as a sphere of transformation. ${ }^{35}$ Korean interiority, in other words, effectively turns into an object of access as it is rendered flexible, plastic, and ultimately compatible with the ideological drive of the empire. ${ }^{36}$

The Japanese Empire is represented in these works as the center of an expanding network of progress and movement to which the Korean ethnic body lends its meaning as an important dynamic element. The empire as space offers the promise of opportunity and potential, so the Korean people are no longer constricted either by ethnic difference or by geographical marginality. Instead, they are on board perpetually moving vessels, traversing along the lines and arteries of empire. ${ }^{37}$ To become an imperial subject, according to this dominant cinematic discourse, is to take part in an imperial project that guarantees the total meaning of existence. Cinematic representations thus typically highlight a moment of decision when a Korean individual has the privilege of attaining the grand meaning of his or her life. The Korean character-initially portrayed as hesitant-undergoes radical transformation and emerges as a figure determined and shaped by the colonial machinery of assimilation. That said, colonial cinema highlights the efficient and "positive" workings of a Japanese-Korean interface that promises a connection between the parochially defined Korean population and the plenitude of affirmative meanings called "the empire." 38

\section{COLONIAL SPACE IN POSTCOLONIAL CINEMA}

In contrast, postcolonial cinema expresses a political ideology of anticolonial nationalism, repudiating the spatial aura, ambiance, and imagery associated with the empire. ${ }^{39}$ Just as the question of imperial ideology is closely tied to the particular spatialization of Korea and Korean subjects in colonial cinema, the oppositional politics of postcolonial cinema can be conceptualized by recourse to the aesthetics of the colonial space. Postcolonial cinema's nationalist orientation rests on the systemic rendition of Korea as an occupied but porous space where Koreans can carve out sites of resistance and integrity. In other words, postcolonial cinema negates the greater reach of the colonial power, that is, its infiltration into the "minds" of the Koreans, by setting up a countervailing way of looking that reorganizes colonial space for Korean alterity. For instance, whereas late colonial cinema employed a positive aura of luminosity to render natural the imperial ideology of 
integration and union, postcolonial films are characterized by a heavy atmosphere of pessimism and darkness that envelops the colonial space. ${ }^{40}$

The Japanese occupation of Korea is shown as pervasive, continuous, and total, while the Korean resistance is shown to be sporadic, yet ubiquitous. This portrayal of occupation and resistance signifies a resistant attitude toward the positive discourse of domination propagated by the colonial government. In particular, it depicts the structural misalignment between the colonizer Japan's rhetoric of benevolence and Koreans' own pessimistic sense of reality. South Korean films on the colonial past constitute a conscious endeavor to challenge a colonial power defined in terms of panoptic vigilance. National authenticity as they narrate it, for instance, is grounded particularly in acts of disruption or disturbance in the supposed field of control and occupation. In this context, such disruption means more than political resistance: it refers to an intraethnic practice of viewing and understanding that films prompt and naturalize to mark the essential difference of Koreans, as a collectivity, from the Japanese. This dialectic between the permeating presence of power and a porous and ever-protean type of resistance forms the important thematic axis around which many postcolonial film narratives revolve. ${ }^{41}$ In other words, the visualization of colonial space as the contentious site of both domination and incessant challenges to that domination informs the most enduring postcolonial imaginary of colonialism onscreen.

According to Partha Chatterjee, in anticolonial nationalism it is the inner, psychic domain that holds the unchanging "essential marks of cultural identity." ${ }^{42}$ Postcolonial cinema shows adherence to the binary opposition that Chatterjee elucidates but further complicates the discursive picture of nationalism. As noted above, colonial cinema brought its focus to and thereby preempted the "inner domain" of the Korean subject as the foundation of allegiance to the empire. In contrast, postcolonial cinema reconfigures the coordinates of interiority and exteriority to thwart that aggressive construction of Korean psychic interiority. It effectively counters the presupposed access to the minds of Korean people as placeholders for the collective essence. Gestures of loyalty are perfunctory and often complemented by a subservient demeanor, typifying the activities of Koreans exposed to the surveillance of the colonial power. This facade or appearance of allegiance is a guileful tactic that aims to deceive the Japanese onlooker. Concurrently, the capacity of Korean people to recognize acts of duplicity on the part of other Koreans becomes an important component in the postcolonial depiction of the colonial past. The "intention to deceive" the anonymous colonial scopic power hence is integral to the fabric of the postcolonial imagination of the Korean collective. Whereas late colonial films obsessively feature the appearance of the Korean imperial subject as a true register of his or her interior state, postcolonial cinema presupposes the split between outer comportment and inner feeling as necessary for the colonized to maintain their integrity. That said, the postcolonial representation of colonialism rests on the premise of guileful subjects and their 
collective recognition of each other's true inclinations. The space of Koreans dispossessed by colonial domination is defined simultaneously by the colonial gaze of surveillance and patrol and by the capacity of the colonized to deflect the efficacy of the scopic intrusion.

The convoluted or distorted visual fields of postcolonial cinema become evident when we draw attention to the way colonial urban space is depicted in visual terms. What to include and exclude from the visual and spatial register already predetermines the parameters of action, issues, and problematics. One of the most conspicuous features of representation in these films is the systematic exclusion of Japanese signage and language from the cityscapes of colonial Korea. After liberation - and until recent years - the Japanese language, either in spoken form or in literal signs, was almost completely absent from the Korean film screen. ${ }^{43}$ The excision of Japanese signage from view may at first appear elemental and incidental, but the logic behind it has significant implications for the representation of the colonial space. The underlying assumption is that Japanese signage does not simply depict the Japanese cultural presence in colonial Korea. It exemplifies the larger visual matrix associated with the colonial modernization that Japan implemented in Korea. It represents the powerful network of linguistic groups and communities in operation, and signals its deep penetration into the daily lives of the Korean people under colonial domination. Postcolonial censorship practices often blocked the visibility of Japanese signage to suppress reminders of that larger colonial network.

At the same time, postcolonial films that depict colonial urban space often show Koreans' willful lack of interest in the urban modernity introduced by the colonial power. Missing in renditions of colonial Seoul is the fascinated gaze of Koreans upon the modern technological innovations that are central to cultural discourses of the colonial urban experience. ${ }^{44}$ Transportation, communication, and information, all of which signal the compression of time and space, rarely occupy the center of attention. South Korean films therefore are out of keeping with the conventional optics of urban modernity that popular cinema habitually thematizes. Early modern cinema, to borrow Kristin Whissel's term, was part of "a broader network of multiple forms of traffic," as it reflected and contributed to "networks and grids that linked individual technologies into expanding systems." 45 Prior to the 20oos, South Korean colonial-themed films did not engage meaningfully with this aspect of colonial development-that of a broader network and its traffic, which necessarily implies the expanding domination of colonial power. ${ }^{46}$

A "negative space" of austerity filled the consequent gap in the representation of colonial urban space. This negative space reflected a recurring sensibility with regard to the depiction of colonial space that transcended individual genres and film cycles. Specifically, it refers to such places as dark passages, back alleys, underground meeting places, and abandoned houses, all of which appear as the backdrop for Korean individual or group action in films set in colonial Seoul. 
Presented in a manner that underscores their darkness and emptiness, these places are temporary destinations for Koreans who are scattering and fleeing rather than sites where they can gather for ordinary social interactions. ${ }^{47}$ In contradistinction to the traffic-ridden "boulevard" space, they presuppose a sense of disconnection and alienation that informs the complex psychological attitudes of Koreans toward the empire. ${ }^{4}$ These films have not merely rendered darkness metaphorically in tandem with nationalist descriptions of history of the colonial period as a "dark time." Rather, the spatial aura suggests ways in which the colonial subject carved out a sphere of alterity within. ${ }^{49}$

One must account for an additional feature that complements the evasion of colonial power that is possible in negative space. These films portray Koreans as capable of staging cunning deceptions against the colonial authorities. Central to their performative gestures is the relay of an intraethnic gaze of recognition that reinforces the hidden Korean alterity and insulates it from external intrusion. This feature is particularly salient when placed against the backdrop of colonial cityscapes. The austere texture of colonial urban space is not designed to show the interior psyche of any particular Korean individual. It lacks the kind of psychologization one may find in the dark urban space of American film noir. Instead, it refers to the general condition of Korea under the supposed colonial surveillance (hence lethargic, defeated, bleak, and intimidating). That space then serves as the ground for staging the self-consciously oppositional actions of the Korean collective. The Korean characters recognize each other's deceptive tactics in demonstrating the required subjection to the colonial authority, and this recognition anchors their intraethnic affinity and trust. Whereas late colonial collaborationist films give the interior space of the Korean national full complexity, postcolonial films project a "superficial" colonial world, devoid of any interior substance. By rendering the colonial space as affectively blank, the films underscore the narrative's focus on Korean subjects' guileful tactics of dissimulation. Hence, the negative space of austerity is an aesthetic precept in postcolonial cinema: it limits the scope of the intense and aggressive colonial gaze in late colonial cinema by refashioning the set of relations that made up the social existence of Koreans under the colonial authority.

\section{THE 1960s: NORMALIZATION AND THE COLD WAR}

This type of refashioning becomes particularly salient in the films made around or after the 1965 normalization treaty with Japan. With the exception of the first chapter-on the biopic genre-I organize the chapters of this book around this event and its aftermath to bring into focus the various and evolving conventions of colonial representation onscreen. The treaty formally brought together the former colonizer and the colonized on an equal plane in Cold War geopolitics and facilitated political alliance and economic partnership between the two states under the 
leadership of the United States. This historic event had a far-reaching impact on South Korean society, as there was fervent protest against rapprochement. It also inspired new cultural productions that revisited the colonial past and the mandate of decolonization by imagining and visualizing Japan as the colonizer in new ways onscreen. But it was the rendition of colonial space in particular that attained a new level of complexity, as it reorganized the parameters of disavowal toward Japan as simultaneously the former enemy and the contemporaneous strategic partner.

A crisis of representation of colonialism in the 1960 s resulted from the rupturing of an anticolonial imaginary that, in the previous decade, had sustained a rather facile scenario of opposition. South Korea's refiguration of the former enemy can be traced in part to the shift in focus toward new privileged sites that, while adhering to the aforementioned negative dynamics, entailed reflection upon the perplexing development of new, neighborly exchanges with Japan. Another area of change was genre. Since genre presupposes a unique yet understandable semantic field of action, reaction, and resolution, the emergence of new genres supposed an amalgamation of discursive views and attitudes in the making of the colonial imaginary. Above all else, the genre and genre-like films of the 196os produced familiar and conventional sites with established meanings and associations that referred to the repressed visual culture of the colonial era. My reading hence moves progressively toward the question of a historical divide before and after normalization and the repression that increasingly came to the fore in film in the aftermath of the normalization treaty and South Korea's assignment of a position in the Cold War world order.

\section{ROADMAP FOR THIS BOOK}

In film, the original political dictate of overcoming Japanese colonialism resulted in a complex and diffused visual rendition that simultaneously projected various terms of engagement with the former colonizer. However limited or problematic in its effect, this popular new cinematic imagining of the colonial therefore constituted a fertile cultural site in which global pressures and local responses entailed creative and complex terms of dialogue and negotiation. "Japanese color," or the intrusion of Japanese imagery, culture, and language into Korean life through Japanese, Korean, and even US films and other cultural productions, was banned to varying degrees in the postcolonial Korean state and was the subject of prolonged controversy. Relations of postcolonial Koreans to their colonial past have been complicated and emotionally fraught. I follow these relations through discourse of the postcolonial period and relate them to a reading of three main genres of the decade: Manchurian action films, kisaeng and gangster films, and revenge horror films. As my analysis of the 196os' volatile cultural discourse and films will indicate, a general crisis concerning the representation of colonialism also led to prolonged debate on the national and cultural identity of South Korean cinema. 
Chapter 1 focuses on the hero narrative of two nationalist films from two distinct eras: the liberation period and the postwar period. The primary films under analysis are Choe In'gyu's Hurrah! For Freedom (1946) and Shin Sangok's The Independence Association and Young Syngman Rhee (1959). My exegesis draws attention to these works' shared themes as well as the lacunae of the official anticolonial history of South Korea. These films introduce and conventionalize the dominant narrative of resistance, struggle, and sacrifice by contrasting the alternative space for populist nationalism and political activism to the downtrodden and enclosed realm of the failing dynastic authority. In tandem with an enlightenment discourse of progress, the rise of a public sphere in these films informs the spatial practice of nationalism and casts a definitive shadow on the subsequent configuration of colonial space in South Korean cinema.

Chapter 2 moves on to the topic of the crisis of national culture and cinema in the 1960 s by focusing on the incursions of Japanese culture and film into South Korea. This section draws close attention to discourses and censorship cases that relate to both the importation of Japanese films and the appearance of "Japanese color" in Hollywood and South Korean films. The April Revolution of 1960 ushered in bifurcating interests with regard to Japan. The chapter chronicles the complex and convoluted passage toward the formation of a rapprochement with Japan and its cultural ramifications. Through readings of the era's controversies in film, I illustrate how the suppressed legacies of colonial visual culture emerged in this period, complicating decolonization in South Korea as the nation became deeply entangled in the intensifying bipolar politics of the Cold War.

The subsequent chapters focus closely on specific cinematic representations. Chapter 3, on the Manchurian action film, examines the shifting logic of the anticolonial struggle in the 196os. First, I introduce and explicate the popular appeal of this adventure narrative, akin to the American western film, which offers the fantasy of individual freedom and service to a national authority in exile. The advent of the Manchurian action film hence might seem to mark an effort to stage the old straightforward form of anticolonial nationalism. Yet excessive moments of loss and despair inform a profound equivocation on the efficacy of the nationalist endeavor. The second part of the chapter interrogates the persistent theme of political economy that dominates the adventure narrative, namely the pursuit of war funds as the sole goal of the nationalist armed struggle. I approach the Manchurian action film as a unique form of war narrative movie in which the capitalist logic of primitive accumulation, state authority formation, and the structuring of desire all converge and intensify.

Chapter 4 examines popular tropes of two key types of socially marginal bodies in the colonial imagination: the kisaeng courtesan and the gangster boss. The film cycles that featured these characters emerged after South Korea's 1965 normalization with Japan. As such, they proceed through an alternate matrix of social interaction and conflict between Koreans and Japanese, typically set in an urban center 
of culture, commerce, and leisure. The chapter draws particular attention to the legendary gangster boss and folk hero Kim Tuhan, whose exploits in widely popular hagiographical narratives inspired numerous film series. My reading of the films traces the displacement of larger political tensions onto a compressed zone of proximity where the Japanese could be checked and restrained from encroaching on the autonomy of Korean commerce and business.

The issue of marginal sites leads to the final chapter's inquiry into stories of vengeance and an exploration of the troubling remnants, or splintered logic, of colonial imagination. Stories of vengeful figures and their return-often in the form of a female specter-trouble the dominant imaginary of the colonial experience that other groups of films have promulgated. The two films under discussion, Yeraishang and Epitaph, both feature a return of the repressed from the colonial past that scandalously exposes aspects of that past. In doing so, they implicitly critique the developmentalist logic of the Cold War, which, aiming at moving forward with Japan as an ally and trade partner, suppressed attempts to reflect on the colonial legacy and right the wrongs of colonial violence. This treatise thus concludes with these films' divergent histories of the nation that constitute a heretical but productive contribution of national cinema to Korean society. 